it may be best to rely on a drug such as chlorpromazine with an established reputation and familiar and predictable effects. The key to control is the adequacy of the initial dose or doses. Finally, the doctor should play it cool and, if at all possible, avoid going it alone. These precautions are axiomatic. There is little merit in posthumous awards for gallantry.

1 State Hospital, Carstairs: Report of Public Local Inquiry into Circumstances Surrounding the Escape of Two Patients on 30 November 1976 and into Security and other Arrangements at the Hospital. Edinburgh, HMSO, 1977.

2 British Medical fournal, 1977, 2, 1374

3 Confederation of Health Service Employees, The Management of Violent or Potentially Violent Patients. Report of a special working party. Banstead, COHSE, 1977.

\section{Ocular hypertension}

Primary glaucoma remains an important cause of blindness in Britain: it accounts ${ }^{1}$ for $7 \%$ of all new blind registrations and $10 \%$ in the age group 50-64. By far the most common type is chronic simple glaucoma-a degenerative disease of unknown aetiology in which increased intraocular pressure is assumed to result from progressive failure of the mechanism for aqueous outflow from the eye. ${ }^{2}$ Population surveys have shown that this disease affects about 250000 people in Britain. ${ }^{34}$

Chronic simple glaucoma is a silent disease, rarely producing symptoms until well advanced with extensive field loss in one eye at least. The diagnostic features are an intraocular pressure greater than $21 \mathrm{~mm} \mathrm{Hg}$, enlargement of the optic cup, and visual field loss. Because of its high prevalence and morbidity, much effort has been expended on discovering the natural history of the disease as well as identifying those who run the greatest risk of developing it.

Surveys ${ }^{356}$ show that $8-10 \%$ of the population over 40 years have intraocular pressures persistently above $21 \mathrm{~mm} \mathrm{Hg}$ without other signs of glaucoma-so-called ocular hypertension. Until recently all such cases were seen as "early" chronic simple glaucoma; in time, it was thought, enlarged optic cups-glaucomatous cupping-and field loss ${ }^{78}$ would inevitably develop. Follow-up studies have shown, however, that this progression does not always occur; indeed some eyes become normotensive. ${ }^{9}$ Furthermore, by no means every patient who develops chronic simple glaucoma can be shown to have had years of ocular hypertension. ${ }^{10}$ Actuarial analysis shows that the number of people with ocular hypertension in the general population is far more than would be expected to develop obvious chronic simple glaucoma. ${ }^{3}$ Even so, someone with ocular hypertension does seem to run a higher risk of developing chronic simple glaucoma than does a normotensive person, and the higher the intraocular pressure the greater the risk. ${ }^{11} 12$

When trying to decide which patients with ocular hypertension will, if untreated, develop glaucomatous cupping and field loss the ophthalmologist relies on several clinical signs. There are some characteristic changes that precede the development of readily detectable field loss. The optic cups, which are normally similar in shape $\mathrm{e}^{13-15}$ and have a diameter of less than 5/10 that of the optic disc, ${ }^{15}{ }^{16}$ gradually enlarge. This glaucomatous enlargement is typically along the vertical axis, ${ }^{16-19}$ producing asymmetry between the optic cups of the two eyes, ${ }^{20} 21$ and differs from the circular enlargement that occurs with age. ${ }^{22} 23$ Serial fundus photography has shown progressive loss of the retinal nerve-fibre layer in patients with ocular hypertension who subsequently develop field loss. ${ }^{24}$ Some people with ocular hypertension fare less well than those with normotensive eyes on colour vision testing ${ }^{25}$ and visual acuity gratings, ${ }^{26} 27$ which suggests that they may in fact have chronic simple glaucoma.

The diagnosis of ocular hypertension calls for an annual review of the intraocular pressure and the appearance of the optic discs, and testing of the visual fields. Long-term antiglaucoma treatment is not without complications, however, and treatment should be reserved for patients with abnormal signs and those considered at special risk for other reasons.

Who are these high-risk patients? Firstly, those with very high intraocular pressures seem more likely than others to develop field loss. ${ }^{11} 12$ Secondly, close relatives of patients with glaucoma have a tenfold increase in risk, ${ }^{28} 29$ and the incidence of the disease is also higher in patients with myopia ${ }^{30}$ and diabetes $^{31}$ than in the general population. Thirdly, several markers have been proposed for identifying patients (normotensive as well as those with ocular hypertension) who may be expected to develop chronic simple glaucoma.

In a small proportion of normal individuals ${ }^{32} 33$ and most patients with chronic simple glaucoma ${ }^{33} 34$ the intraocular pressure rises after they have been given topical steroids. This response is thought to be diagnostic of glaucoma or future glaucoma. ${ }^{34}$ Normal intraocular pressures undergo diurnal variation, ${ }^{35}{ }^{36}$ closely following changes in plasma cortisol concentrations ${ }^{37}$; and this variation is increased in patients with chronic simple glaucoma, suggesting altered ocular sensitivity to plasma cortisol. ${ }^{38}$ The plasma cortisol concentration is more easily suppressed in patients with glaucoma, ${ }^{3940}$ and has been suggested as a predictive test for glaucoma. ${ }^{39}$ Moreover, patients with glaucoma have been reported by some $e^{41-43}$ but not by others ${ }^{44} 45$ to show an abnormally high incidence of steroid-induced inhibition of lymphocyte transformation. The relation between the "steroid response" and chronic simple glaucoma is, however, still in doubt; as yet no long-term study of steroid responders has shown large numbers progressing to chronic simple glaucoma. ${ }^{46}$ Finally, the trabecular meshwork of eyes with steroid-induced glaucoma is quite different from that of eyes with chronic simple glaucoma. ${ }^{4 ?}$

Two further screening tests have been described recently, based on the extent of the fall in intraocular pressure after topical adrenaline ${ }^{48}$ and a possible link between glaucoma and HLA B12 and HLA B7.49 Both associations require further evaluation before we can assess their usefulness for clinical screening.

${ }^{1}$ Sorsby, A, Health Trends, 1973, 5, 7.

2 Duke Elder, S (ed), System of Ophthalmology, vol IX. London, Kimpton, 1969.

${ }^{3}$ Hollows, F C, and Graham, P A, British fournal of Ophthalmology, 1966, 50, 570.

${ }^{4}$ Bankes, J L K, et al, British Medical fournal, 1968, 1, 791.

5 Norskov, K, Acta Ophthalmologica, 1970, 48, 401.

${ }^{6}$ Strömberg, U, Acta Ophthalmologica, 1962, suppl 69.

? Leydhecker, W, Documenta Ophthalmologica, 1959, 13, 359.

${ }^{8}$ Goldmann, H, American fournal of Ophthalmology, 1959, 48, no 1, pt 2, 213.

${ }^{9}$ Perkins, E S, British fournal of Ophthalmology, 1973, 57, 179.

10 Perkins, E S, British fournal of Ophthalmology, 1973, 57, 186.

${ }^{11}$ Schappert-Kimmijser, A, Ophthalmologica, 1971, 162, 289.

12 David, R, Livingston, D G, and Luntz, M H, British fournal of Ophthalmology, 1977, 61, 668.

${ }^{13}$ Witusik, W, Ophthalmologica, 1966, 152, 57.

14 Snydacker, D, American fournal of Ophthalmology, 1964, 58, 958.

15 Armaly, M, American fournal of Ophthalmology, 1969, 68, 401.

${ }_{16}$ Portnoy, G L, American fournal of Ophthalmology, 1975, 80, 51.

17 Kronfeld, P C, in Symposium on Glaucoma, eds M F Armaly et al, chap 3. St Louis, C V Mosby, 1967.

${ }^{18}$ Kirsch, R E, and Anderson, D R, Transactions of the American Academy of Ophthalmology and Otolaryngology, 1973, 770P, 143. 
${ }^{19}$ Weisman, R L, et al, Transactions of the American Academy of Ophthalmology and Otolaryngology, 1973, 770P, 157.

${ }^{20}$ Armaly, M, Investigative Ophthalmology, 1970, 9, 425

${ }^{21}$ Fishman, R S, Archives of Ophthalmology, 1970, 84, 590.

${ }^{22}$ Pickard, R, British fournal of Ophthalmology, 1948, 32, 355.

${ }^{23}$ Schwartz, J T, Reuling, F H, and Garrison, R J, British fournal of Ophthalmology, 1975, 59, 216.

${ }^{24}$ Sommer, A, et al, Archives of Ophthalmology, 1977, 95, 2149.

${ }^{25}$ Lakowski, R, Bryett, J, and Drance, S M, Canadian Fournal of Ophthalmology, 1972, 7, 86.

${ }^{26}$ Arden, $\mathrm{G}$, and Jacobsen, J T, Investigative Ophthalmology, 1978, 17, 23.

27 Arden, G, and Hitchings, R A, Association for Research into Vision and Ophthalmology, Spring Meeting, 1978. Suppl to Investigative Ophthalmology, in press.

${ }^{28}$ Paterson, G L, Transactions of the Ophthalmological Societies of the United Kingdom, 1961, 81, 561.

29 Perkins, E S, British fournal of Ophthalmology, 1974, 58, 529.

30 Deodati, F, Fontan, P, and Mouledous, J M, Archives d'Ophtalmologie, 1974, 34, 853.

${ }^{31}$ Becker, B, American fournal of Ophthalmology, 1971, 71, 1.

32. Armaly, M, Archives of Ophthalmology, 1963, 70, 482.

33 Becker, B, and Mills, D W, Archives of Ophthalmology, 1963, 70, 500.

${ }^{34}$ Palmberg, P F, et al, American fournal of Ophthalmology, 1975, 80, 844.

${ }^{35}$ Henkind, P, Leitman, M, and Weitzman, E D, Investigative Ophthalmology, 1973, 12, 705.

${ }^{36}$ Kitazawa, Y, and Horie, T, American fournal of Ophthalmology, 1975, 79, 557.

37 Weitzman, E, et al, British fournal of Ophthalmology, 1975, 59, 566

${ }^{38}$ Schwartz, B, and Levene, R Z, Archives of ()phthalmology, 1972, 87, 369.

${ }^{39}$ Kass, M A, Krupin, T, and Becker, B, American fournal of Ophthalmology, $1976,82,496$

" Rosenberg, J, and Levene, R, Archives of Ophthalmology, 1974, 92, 6.

${ }^{41}$ Bigger, J F, Palmberg, P F, and Becker, B, Investigative Ophthalmology, $1972,11,832$

42 Bigger, J F, Palmberg, P F, and Zink, H A, American fournal of Ophthalmology, 1975, 79, 92 .

${ }^{43}$ Foon, K A, et al, American fournal of Ophthalmology, 1977, 83, 167.

${ }^{44}$ Benezra, D, Ticho, U, and Sachs, U, American fournal of Ophthalmology, 1976, 82, 866

45 Sowell, J G, et al, American fournal of Ophthalmology, 1977, 84, 715.

${ }^{46}$ Rohen, J W, Linner, E, and Witmer, R, Experimental Eye Research, 1973, 17, 19.

4 : Wilensky, J T, Podos, S M, and Becker, B, Archives of Ophthalmology, 1974, 91, 200

48 Becker, B, and Shin, D H, Archives of Ophthalmology, 1976, 94, 2057.

${ }^{49}$ Shin, D H, and Becker, B, American Fournal of Ophthalmology, 1976, 82, 871

\section{America's influence on Japanese health}

Anyone who has never been to Japan is likely to have a mental image dominated by Geisha girls, samurai, and tea ceremonies. In reality the dominant feature of life for the 103 million Japanese is their burgeoning industrialisation with its consequences, good and bad, for individuals as the nation forces up its GNP - all set against a backcloth of strong tradition.

Japan presents a unique opportunity for epidemiologists. Medical records are well kept, and medical practice and research are advanced. Indeed, the infant mortality per 1000 live births $^{1}$ is $10 \cdot 8$, well below the United States figure ${ }^{2}$ of $16 \cdot 3$, and clear evidence of the uniformly good standards of care. At the other end of the scale the life expectancy ${ }^{12}$ for Japanese men and women is longer than for American whites. Despite the many ways in which the Japanese have adopted the American way of life the patterns of health and disease remain very different in the two countries. The different relative frequencies of various forms of cancer show this clearly. Recently Wynder and Hirayma ${ }^{3}$ reviewed the patterns of cancer in white Americans and Japanese and looked at some of the factors that might underlie the differences (listing the key references, which will not be repeated here). The changes that have occurred in the present generation have given us what is almost certainly an unrepeatable chance to look at environmental factors with greater relevance for Western man than anything that has emerged from black Africa.

Cancer is the second major cause of death in both countries, with rates of 185 and 173 per 100000 for men and 149 and 129 for women in the United States and Japan respectively. ${ }^{12}$ The rates at specific sites are very different. American men have higher death rates from cancer of the prostate, colon, buccal cavity, skin, lungs, and urinary bladder and from leukaemia. In Japanese men and women there is a higher mortality from cancer of the stomach, oesophagus, and liver. American women have more breast and uterine cancer. The trends show that in both countries deaths from stomach, cervix, rectum, and skin cancers are falling, while in Japan prostate, bladder, intestine, and thyroid cancers are on the increase. Deaths from lung cancer in the Japanese are showing the same steady rise as in white Americans, though they are still only one-tenth of the American figures.

Japanese who have migrated to Hawaii and the United States are a group of particular interest for epidemiologists; for as they come to live in an American environment they adopt many features of its life style, and especially the Western dietary habits. Hawaii is in many ways intermediate between the two cultures. The migrants to the United States show a rise in the incidence of colon and lung cancer and a decline in the frequency of carcinoma of the stomach to half the level in Japan - which is still, however, three times that in whites in Hawaii. ${ }^{4}$

The pattern of mortality from the various types of cancer is also changing in the indigenous Japanese as they become more like the migrants. Carcinogens certainly can arise from modern methods of manufacture and farming, but these major differences in mortality between the United States and Japan, which are obviously not immutable, are more likely to be determined by how people live; eating, drinking, and smoking habits must be prime suspects. Cigarette smoking, as judged by annual tobacco consumption per head, has risen steadily in both countries since 1920, and, though the United States headed the league in 1972 with an annual average of 3738 cigarettes smoked by each adult, Japan was not far behind at 3138. On the other hand, the Japanese do not drink so much alcohol as the Americans-though warm sake could have its own special effects. In smoking and drinking, however, the two groups differ only quantitatively, but their differences in diet are more fundamental. Americans derive $40^{\circ} \%$ of their calories from fat, mainly animal and dairy products, but the Japanese only $20^{\circ} \%$, of which $37 \%$ is unsaturated fat; while over $40 \%$ of their calories come from rice. The Japanese are :ernarkably conservative in their dietary habits, rice and soya bean seing the staple items and fish providing occasional variety. Meat is limited and expensive, and indeed many of the commonplace foods in the West are luxuries for the Japanese. This diet appears to offer the Japanese protection from cancers of the colon and pancreas, which are thought to be linked to a high-fat diet, as are the endocrine-related cancers of the prostate, uterus, and breast. ${ }^{5}$

The change of cancer incidence in migrant Japanese who have adopted an American way of life is, then, strong evidence of the importance of personal habits as a factor in carcinogenesis. It takes a revolution to alter a nation's eating habits; but in Japan the tides of war and the national desire for economic success have done much to change life in other respects during the life span of the present generation, and the changes are now reflected in mortality statistics. On the one hand the rise in living standards has brought about a fall in the incidence of stomach and cervical cancer in Japan, as it has in Western ccuntries; and on the other hand the increase in 